Check for updates

Cite this: RSC Adv., 2017, 7, 29916

Received 8th April 2017

Accepted 3rd June 2017

DOI: 10.1039/c7ra03995f

rsc.li/rsc-advances

\title{
Production of furfural from xylose and corn stover catalyzed by a novel porous carbon solid acid in $\gamma$-valerolactone $\uparrow$
}

\author{
Yuanshuai Zhu, ${ }^{a}$ Wenzhi Li, (D) *a Yijuan Lu, ${ }^{a}$ Tingwei Zhang, (D) a Hasan Jameel, ${ }^{\text {b }}$ \\ Hou-min Chang ${ }^{b}$ and Longlong $\mathrm{Ma}^{\mathrm{c}}$
}

A resorcinol-formaldehyde resin carbon (RFC) catalyst with a well-developed, ordered, mesoporous framework was prepared using a soft template method at room temperature. The carbon was sulfonated in water using sulfanilic acid under mild atmospheric conditions. The sulfonated RFC (S-RFC) was characterized by $\mathrm{N}_{2}$ adsorption-desorption, elemental analysis, TEM, XPS, and FT-IR. It was determined that S-RFC is an efficient solid acid catalyst for furfural production from xylose and corn stover in $\gamma$ valerolactone (GVL). The effects of reaction time, reaction temperature, catalyst loading, substrate dosage and water concentration were investigated. $80 \%$ furfural yield and $100 \%$ xylose conversion were obtained from xylose at $170{ }^{\circ} \mathrm{C}$ in $15 \mathrm{~min}$ with $0.5 \mathrm{~g}$ catalyst. Comparatively, $68.6 \%$ furfural yield was achieved from corn stover at $200{ }^{\circ} \mathrm{C}$ in $100 \mathrm{~min}$ when using $0.6 \mathrm{~g}$ catalyst. Since there was no discernable decrease in furfural yield after multiple conversions utilizing the same catalyst, the recyclability of the catalyst is considered good

\section{Introduction}

This research is driven by the growing environmental concerns associated with burning fossil fuels and the efforts to develop a sustainable and reliable energy source to ensure both the development of society and a greener planet. ${ }^{1}$ Lignocellulosic biomass is an abundant, natural, and renewable resource that has enormous applications in producing higher-value chemicals $^{2,3}$ and biofuels. ${ }^{4-6}$ Lignocellulosic biomass is comprised of three primary components - cellulose, hemicellulose, and lignin - where each component has distinct characteristics and properties that allows it to be tailored to a unique purpose. ${ }^{7}$

Furfural is a versatile chemical derived from pentosane-rich agricultural and forestry residues such as corn cobs, corn stover, saw dust, and straw. Despite the reported concerns in regards to the production of potential biofuels and fuel additives, such as 2-methylfuran, ${ }^{8,9} \gamma$-valerolactone ${ }^{10-12}$ and long chain hydrocarbons, ${ }^{13}$ using furfural as a feedstock, conversion of furfural into valuable chemicals, such as dicarboxylic acid, ${ }^{14-16}$ furfuryl alcohol $^{17}$ and tetrahydrofurfuryl alcohol ${ }^{18}$ - which has broad

${ }^{a}$ Department of Thermal Science and Energy Engineering, University of Science and Technology of China, Laboratory of Basic Research in Biomass Conversion and Utilization, Hefei 230026, P. R. China. E-mail: liwenzhi@ustc.edu.cn

${ }^{b}$ Department of Forest Biomaterials, North Carolina State University, Raleigh, NC 27695-8005, USA

${ }^{\circ}$ CAS Key Laboratory of Renewable Energy, Guangzhou Institute of Energy Conversion, Chinese Academy of Sciences, Guangzhou 510640, P. R. China

$\dagger$ Electronic supplementary information (ESI) available. See DOI: 10.1039/c7ra03995f uses in polymer, rubber, and pharmaceutical applications attracted the interest of many researchers. Ultimately, it is agreed that the production and utilization of furfural would be beneficial for mitigating the energy and environment crisis and increasing profitability of a biorefinery economical profits.

For the first time in 1921, Quaker Oats Company commercially produced furfural from xylose and xylan using $\mathrm{H}_{2} \mathrm{SO}_{4}$ as catalyst. ${ }^{19}$ Since then improvements in furfural production have been made using homogenous catalysts such as mineral acids, ${ }^{20}$ organic acids, ${ }^{21}$ and Lewis acids ${ }^{22-24}$ as well as ionic liquid. ${ }^{25}$ Despite the improvements, the poor recyclability of homogenous catalysts and equipment corrosion they cause hinder their use. To overcome these obstacles, an increasing number of greener, heterogeneous catalysts have been developed.

Under the circumstance, multifarious zeolites were explored and gained more and more popularity in biomass conversion including SBA-15, ${ }^{26}$ functionalized MCM-41 (ref. 27) and Sn$\mathrm{MMT}^{28}$ as well as SAPO- $34 .^{29}$ But hydrothermal stability of zeolites still needs to be improved. Besides, commercial ion exchange resins (Amberlyst-70, Amberlyst-15 and Nafion) were also investigated in detail. ${ }^{30-32}$ Nevertheless, the large-scale industrial applications of ion exchange resin are hindered by low porosity, high price and the poor endurance against high temperature. Moreover, recent years has witnessed a fast development of sugar catalyst, which was typically prepared through a two-step process. ${ }^{33-36}$ These catalysts were expected to be promising in biomass conversion because they are inexpensive, a source of ample and renewable carbon source as well as good acid density. However, the further development is still 
faced with some challenges, such as high sulfonation temperature and low porosity.

Sulfonated ordered mesoporous carbons (S-OMCs) was a good alternative by virtue of well-developed porosity with high specific surface area and symmetrical pore distribution, which provides the appropriate support for catalytic conversion of sugars into chemicals. Many investigations suggested that SOMCs performed well in biodiesel production ${ }^{37,38}$ which was usually prepared via a nanocasting method ${ }^{39,40}$ followed by sulfonation with $\mathrm{H}_{2} \mathrm{SO}_{4}$. It's worth noting that the environmental and safety issues associated with the use of HF to remove the hard templates cannot be ignored. Meanwhile, sulfonation with concentrated $\mathrm{H}_{2} \mathrm{SO}_{4}$ was inefficient and could cause damage to the mesoporous framework. Recently, an easier, safer and milder sulfonation technique was proposed with sulfanilic acid, ${ }^{41}$ which can sulfonate single wall carbon nanotubes under moderate atmospheric conditions effectively. Inspired by their work, we prepared a resorcinol-formaldehyde resin carbon (RFC) using a scaled-up experiment based on previous work ${ }^{42}$ with some minor modifications, followed by mild sulfonation using sulfanilic acid as sulfonation reagent in water to obtain a novel porous carbon solid acid catalyst (S-RFC). During the whole process of catalyst preparation, $\mathrm{HF}$ and $\mathrm{H}_{2} \mathrm{SO}_{4}$ were avoided, which is more efficient and environmental friendly over other similar catalyst. To the best of our knowledge, the novel catalyst (S-RFC) has not been reported for use in biomass conversion.

In this study, a novel porous carbon solid acid was prepared and characterized by various instruments for its physical and chemical properties. The catalyst was utilized to produce furfural from xylose and corn stover. The influences of reaction temperature, reaction time, and catalyst loading were investigated. Bio-based GVL was used as solvent due to its superior properties in biomass utilization. ${ }^{43,44}$ More importantly, GVL can be derived from biomass by a integrated process. ${ }^{45,46}$

\section{Experimental section}

\section{Materials}

D-(+)-xylose (98\%), furfural (99\%), 5-HMF (99\%), sulfanilic acid (AR, 99.5\%) and isoamyl nitrite (95\%) were all purchased from Aladdin. Pluronic F127 $\left(M_{\mathrm{av}}=12600, \mathrm{EO}_{106} \mathrm{PO}_{70} \mathrm{EO}_{106}\right)$ was supplied by Sigma-Aldrich. Hydrochloric acid ( $\mathrm{HCl}, 36-38 \%)$, ethanol (AR), acetone (AR), $N, N$-dimethylformamide (DMF, AR), resorcinol (AR, 99\%), formaldehyde solution (AR, $37 \mathrm{wt} \%$ ) and anhydrous $\mathrm{NaCO}_{3}(\mathrm{AR})$ were obtained from Sinopharm Chemical Reagent Co., Ltd. $\gamma$-Valerolactone (95\%) was provided by LangFang Hawk Technology and Development Co., Ltd. Corn stover was gathered from a cropland located in AnHui Province and cut into pieces, then flushed with running water to remove any impurities. After drying to constant-weight at $80{ }^{\circ} \mathrm{C}$, the corn stover was ground into uniform particles and sieved by a 40 mesh screen.

\section{Synthesis of RFC}

RFC was prepared per the reported method ${ }^{42}$ with slight modifications. In this procedure, $0.056 \mathrm{~g} \mathrm{Na}_{2} \mathrm{CO}_{3}$ and $11.3 \mathrm{~g}$ formaldehyde solution ( $37 \mathrm{wt} \%$ ) was added into a $50 \mathrm{ml}$ roundbottle flask under vigorous agitation at room temperature. After the anhydrous $\mathrm{Na}_{2} \mathrm{CO}_{3}$ dissolved completely, $11.0 \mathrm{~g}$ resorcinol was put into the alkaline solution for pre-polymerization. After $70 \mathrm{~min}$, the solution was poured into a mixture containing $8.0 \mathrm{~g}$ $\mathrm{F} 127,50.0 \mathrm{~g}$ ethanol and $40.0 \mathrm{~g}$ distilled water under stirring. After $10 \mathrm{~min}, 5.0 \mathrm{ml} \mathrm{HCl}(2 \mathrm{M})$ was added into the hybrid to accelerate the polymerization process. After agitation for about 2.2-2.5 min, a turbid mixture appeared which suggested the occurrence of phase separation. The hybrid was further agitated for $60 \mathrm{~min}$ and kept standing overnight to form the sedimentary polymer gel. Finally, the gel was natural withering for $12 \mathrm{~h}$ then aged at $80{ }^{\circ} \mathrm{C}$ for one day. The resulting soft, sticky, orange polymer was calcined under a $\mathrm{N}_{2}$ atmosphere at $350^{\circ} \mathrm{C}$ for $2.5 \mathrm{~h}$ to remove the template (F127) and then at $500{ }^{\circ} \mathrm{C}$ for $4 \mathrm{~h}$ to accomplish the carbonization at a heating rate of $1{ }^{\circ} \mathrm{C} \min ^{-1}$ to obtain the ordered mesoporous carbon (RFC).

\section{Sulfonation of RFC}

Sulfonation of RFC was conducted following the reported procedures $^{41}$ with slight modifications. $3 \mathrm{~g}$ RFC and $12 \mathrm{~g}$ sulfanilic acid were put into a $500 \mathrm{ml}$ round-bottom flask containing $300 \mathrm{ml}$ distilled water. The mixture was heated to $80{ }^{\circ} \mathrm{C}$ then $6 \mathrm{~g}$ isoamyl nitrite was added once the sulfanilic acid was completely dissolved. The mixture was agitated vigorously overnight at $80{ }^{\circ} \mathrm{C}$ and then cooled to room temperature for filtration. The filter cake was washed with distilled water, ethanol and acetone repeatedly till the filtrate was clear. The catalyst was collected and sonicated in DMF $(50 \mathrm{ml})$ for $20 \mathrm{~min}$ to eliminate any residual substrates. The black solid powder was isolated by filtration and swilled with acetone several times and then dried in vacuum oven. The obtained samples were donated as S-RFC.

\section{Catalyst characterization}

Both RFC and S-RFC were characterized by FT-IR (Nicolet 8700 (KBr disks)), BET (Tristar II 3020), XPS (Thermo Scientific ESCALAB 250Xi), TEM (JEM 2010 electron microscope) and elemental analysis (EA, Elementar model Vario EL III). Since sulfur existed in the single form of $-\mathrm{SO}_{3} \mathrm{H}$, per XPS, the amount of $-\mathrm{SO}_{3} \mathrm{H}$ was determined by the mole of sulfur present within the carbon support and calculated by elemental analysis.

\section{Typical procedure for furfural production from xylose and corn stover}

Experiments for furfural production from xylose and corn stover were implemented in a $100 \mathrm{ml}$ mechanical stirring zirconium autoclave equipped with a PID temperature controller. Different proportions of catalyst, substrate, and solvent were charged into the reactor. The sealed reactor was heated to a given temperature and maintained for different time duration with a rotation of $500 \mathrm{rpm}$. The reaction ended by immersing the autoclave in a water bath to cool the reaction mixture to room temperature rapidly. Afterwards, the reaction mixture was filtered and the filtrate was preserved in a refrigerator for subsequent analysis by means of HPLC. 


\section{HPLC analysis of furfural, HMF and xylose}

The concentration of products (furfural and HMF) in the filtrate was determined using a high-performance liquid chromatograph (Waters 515 pump) equipped with a Waters Symmetry®C18 column and an Ultraviolet Detector (Waters 2489) at a wavelength of $280 \mathrm{~nm}$. A mixture of methanol/water with a volume ratio of $2 / 3$ was used as eluent flowing at $0.4 \mathrm{ml} \mathrm{min} \mathrm{m}^{-1}$ and the temperature of column oven was set as $30^{\circ} \mathrm{C}$. The concentration of xylose was determined separately using highperformance liquid chromatograph (Waters 515 pump) that was equipped with a Waters XBridgeTM Amide column and a refractive index detector (Waters 2414). Both the column oven and the detector were kept at $45{ }^{\circ} \mathrm{C}$. Acetonitrile/distilled water $(3 / 2, \mathrm{v} / \mathrm{v})$ served as mobile phase and was run at $0.4 \mathrm{ml} \mathrm{min}^{-1}$. Pre-constructed calibration curves were used for quantitative analysis and xylose conversion, furfural yield, furfural selectivity and HMF yield were calculated as shown below:

$$
\begin{aligned}
& \text { Xylose conversion }=(1-\text { moles of xylose remained } / \\
& \text { moles of starting xylose }) \times 100 \%
\end{aligned}
$$

Furfural yield (from xylose $)=($ moles of furfural produced $/$ moles of starting xylose) $\times 100 \%$

Furfural selectivity $=($ furfural yield/xylose conversion $) \times 100 \%$

Furfural yield (from corn stover) $=$ (moles of furfural produced $/$ moles of starting xylan in corn stover $) \times 100 \%$

HMF yield (from corn stover) $=$ (moles of HMF produced/ moles of starting glucan in corn stover $) \times 100 \%$

\section{Results and discussion}

\section{Characterization of the carbon solid acid catalyst}

Physical properties of RFC and S-RFC are listed in Table 1. RFC presented a well-developed porous structure with specific surface area, pore volume, and average pore diameter of $604 \mathrm{~m}^{2} \mathrm{~g}^{-1}, 0.72$ $\mathrm{cm}^{3} \mathrm{~g}^{-1}$, and $4.78 \mathrm{~nm}$ respectively. After sulfonation, different levels of decline occured to various parameters but S-RFC still maintained an excellent porous framework and its BET parameters were $530 \mathrm{~m}^{2} \mathrm{~g}^{-1}, 0.56 \mathrm{~cm}^{3} \mathrm{~g}^{-1}$, and $4.2 \mathrm{~nm}$ respectively. The grafted $\mathrm{SO}_{3} \mathrm{H}$, occupying some pore space, might be the reason for this decrease. It was concluded because of the modest decline in these parameters that sulfonation does not cause a serious collapse or deconstruction of the pore structure.

Mesopores were clearly visible in the TEM images (Fig. S1 in ESI $\dagger$ ). The ordered mesoporous structure was confirmed by the

Table 1 Textural parameters of RFC and S-RFC

\begin{tabular}{llll}
\hline Entry & $\mathrm{S}_{\mathrm{BET}}\left(\mathrm{m}^{2} \mathrm{~g}^{-1}\right)$ & $\mathrm{V}^{a}\left(\mathrm{~m}^{3} \mathrm{~g}^{-1}\right)$ & $\mathrm{D}^{b}(\mathrm{~nm})$ \\
\hline RFC & 604 & 0.72 & 4.78 \\
S-RFC & 530 & 0.56 & 4.2 \\
\multicolumn{2}{c}{${ }^{a}$ Pore volume. } & ${ }^{b}$ Average pore diameter. &
\end{tabular}

uniform distribution of honeycomb-shaped hexagonal pores and stripe-like channels. In addition, Fig. $\mathrm{S} 1 \dagger$ also illustrates the mesoporous structure was well preserved after sulfonation because no serious collapse and deconstruction of pores and channels was discovered between image A and image B, proving that the sulfonation technique was mild and efficient, which was consistent with the BET results. Besides, these wellpreserved pore channels could provide abundant reaction places during reactions, which promotes the diffusion and adsorption of xylose molecules.

Table 2 shows the elemental composition of RFC and S-RFC. A trace amount of nitrogen was incorporated into RFC, most likely during calcination since it was calcined in a $\mathrm{N}_{2}$ atmosphere. This trace amount of nitrogen was enriched to some extent in the sulfonated RFC. It has been demonstrated that sulfonation of carbon with sulfanilic acid and isoamyl nitrite result in the direct incorporation of aromatic ring to the $\mathrm{Sp}^{2}$ carbon of amorphous carbon, and the presence of the trace amount of nitrogen must be due to the surface contamination. ${ }^{\mathbf{4 1}}$ Sulfonation also resulted in an incorporation of sulfur, as expected, and the concomitant increase in oxygen and hydrogen contents as can be seen in Table 2 .

In FT-IR spectrum of RFC and S-RFC (Fig. S $2 \dagger$ ), the characteristic peaks at 1124,1185 , and $1220 \mathrm{~cm}^{-1}$ can be ascribed to $\mathrm{SO}_{3} \mathrm{H}$ groups. The bands at 1035 and $1011 \mathrm{~cm}^{-1}$ represented $\mathrm{S}=\mathrm{O}$ asymmetric and symmetric stretching vibrations respectively. ${ }^{47}$ This confirms that $-\mathrm{SO}_{3} \mathrm{H}$ groups had been successfully grafted into the carbonaceous material, ${ }^{48}$ which was in good agreement with results of elemental analysis and XPS. In addition, the small band at $3470 \mathrm{~cm}^{-1}$ in RFC is most likely attributed to incomplete carbonization. The stronger absorption at $3430 \mathrm{~cm}^{-1}$ is due to the $\mathrm{OH}$ stretching of the sulfonic acid.

Fig. S3† shows S 2p XPS spectrum of S-RFC, which was carried out to establish the valence state of sulfur. The single peak at $168.7 \mathrm{eV}$ illustrates the existence of $\mathrm{SO}_{3} \mathrm{H}$ species in $\mathrm{S}$ RFC, ${ }^{49}$ and all the sulfur atoms were confined to $-\mathrm{SO}_{3} \mathrm{H}$ groups. Therefore, the density of $\mathrm{SO}_{3} \mathrm{H}$ was estimated based on sulfur content in elemental analysis.

\section{Effect of reaction temperature and residence time on xylose conversion, furfural yield and furfural selectivity}

Xylose dehydration was conducted in a well-sealed autoclave equipped with a stirrer and a PID temperature controller capable of achieving various temperatures $\left(150{ }^{\circ} \mathrm{C}, 160{ }^{\circ} \mathrm{C}\right.$, $170{ }^{\circ} \mathrm{C}$, and $180{ }^{\circ} \mathrm{C}$ ) within a time duration from 5 to $30 \mathrm{~min}$ with $0.5 \mathrm{~g}$ catalyst, $0.8 \mathrm{~g}$ xylose, and $32 \mathrm{ml} \mathrm{GVL}$. Fig. 1 illustrated that reaction temperature and residence time play a vital role on xylose conversion, furfural yield and furfural selectivity. The effect of temperature was also significant. As you can see from Fig. 1B, xylose conversion reached $95 \%$ at a reaction temperature of $150{ }^{\circ} \mathrm{C}$ within 15 minutes. The time required for complete conversion of xylose at $150{ }^{\circ} \mathrm{C}, 160{ }^{\circ} \mathrm{C}, 170{ }^{\circ} \mathrm{C}$ and $180^{\circ} \mathrm{C}$ was $20 \mathrm{~min}, 15 \mathrm{~min}, 10 \mathrm{~min}$ and $5 \mathrm{~min}$, respectively. The furfural yield and furfural selectivity follow identical trends to the conversion of xylose as seen in Fig. 1A and C. Both furfural 
Table 2 Empirical formula of RFC and S-RFC based on elemental analysis data

\begin{tabular}{|c|c|c|c|c|c|c|}
\hline & \multicolumn{5}{|c|}{ Elemental composition (\%) } & $\mathrm{SO}_{3} \mathrm{H}$ acidity ${ }^{a}\left(\mathrm{mmol} \mathrm{H} \mathrm{H}^{+}\right.$per $\left.\mathrm{g}\right)$ \\
\hline S-RFC & 73.02 & 3.91 & 20.168 & 0.20 & 2.754 & 0.86 \\
\hline
\end{tabular}

yield and furfural selectivity increase with residence time and reach a maximum at a given temperature at $15 \mathrm{~min}$. After $15 \mathrm{~min}$, both yield and selectivity declines at higher temperatures $\left(170\right.$ and $\left.180{ }^{\circ} \mathrm{C}\right)$ but stabilize at lower temperatures $(150$ and $160^{\circ} \mathrm{C}$ ). Noteworthy, the maximum furfural yield of $80 \%$ was obtained at $170{ }^{\circ} \mathrm{C}$ for $15 \mathrm{~min}$. In addition, the lower furfural yields at 150,160 and $180^{\circ} \mathrm{C}$ compared to that of $170^{\circ} \mathrm{C}$ suggested that side and yield loss reactions compete more favourably at these conditions. Previous studies have proposed three main yield loss reactions limiting the final furfal yield as illustrated in Scheme $1,^{50-52}$ including fragmentation, resinification and condensation. Specifically, lower temperatures $\left(150{ }^{\circ} \mathrm{C}, 160{ }^{\circ} \mathrm{C}\right)$ decelerate the conversion of reactants, which possibly benefits the condensation between xylose (or intermediates) and formed furfural molecules, resulting in decreased furfural yield. However, although higher temperature $\left(180{ }^{\circ} \mathrm{C}\right)$ promoted xylose conversion, fragmentation and resinification of furfural into resinous products were enhanced as well possibly because of the stronger molecular thermal motion, ${ }^{48}$ which also explained the observation that the reaction mixture produced a deeper color at $180{ }^{\circ} \mathrm{C}$ compared with the lower temperatures as seen in Fig. 1A.

Controlled experiments using no catalyst, RFC were also carried out using the optimal condition for xylose conversion to furfural $\left(170^{\circ} \mathrm{C}, 15 \mathrm{~min}\right)$. The results are illustrated in Table 3 . Without the presence of the catalyst, only a trace amount of furfural was formed. Similar result was also obtained using RFC as a catalyst, demonstrating the importance of the $-\mathrm{SO}_{3} \mathrm{H}$ bearing catalyst for furfural production. Also, shown in Table 3 is the significance of keeping the reaction system under anhydrate conditions because an addition of $4 \mathrm{ml}$ of water in the system significantly decreased the yield of furfural.

In order to make clear the effects of water on furfural formation, experiments with different water concentrations were conducted at $170{ }^{\circ} \mathrm{C}$ for $15 \mathrm{~min}$. The results are shown in Table 4 . The furfural selectivity was found to decrease from $80.8 \%$ to $39.4 \%$ as the water concentration increased from $1 \mathrm{ml}$ to $4 \mathrm{ml}$, which verified that water has a negative impact on furfural selectivity. On the other hand, prolonging reaction time to $30 \mathrm{~min}$ in $32 \mathrm{ml} \mathrm{GVL}$ containing $6 \mathrm{ml} \mathrm{H}_{2} \mathrm{O}$ resulted in the highest furfural yield and selectivity of $63 \%$ and $65 \%$, respectively, which are still lower than those in pure GVL $(80 \%$ and $80.8 \%$ ). Thus, it can be concluded that the lower furfural yield was caused by lower furfural selectivity instead of reaction rates.

\section{Effect of various acid catalysts on furfural production}

The S-RFC was also experimentally compared with three homogenous acid $\left(\mathrm{HCl}, \mathrm{H}_{2} \mathrm{SO}_{4}, \mathrm{PTSA} \cdot \mathrm{H}_{2} \mathrm{O}\right)$ and three solid acid catalyst (PTSA-POM, Amberlyst-15, H-Beta) at $170{ }^{\circ} \mathrm{C}$ for $15 \mathrm{~min}$ in GVL and the result was depicted in Table 5. Compared with homogeneous acid ( $\mathrm{HCl}, \mathrm{H}_{2} \mathrm{SO}_{4}$, PTSA), S-RFC showed superior catalytic performance and easier recyclability, affording a furfural yield of $80 \%$ from xylose. The high propensity of furfural towards to polymerization in strong acid system might be the cause for the inferior performance of mineral strong acids. ${ }^{50}$ Among the tested heterogeneous acid, S-RFC also performed better in view of its superior porous structures and good acidity. Overall, S-RFC is an efficient heterogeneous catalyst for furfural formation in a green solvent GVL.

Compared with the conventional sulfonation method (i.e., boiling in concentrated $\mathrm{H}_{2} \mathrm{SO}_{4}$ ), the sulfonation with benzenesulfonic acid radical generated by the diazo-reaction between sulfanilic acid and isoamyl nitrite can be carried out under relatively moderate reaction conditions, which effectively avoids the collapse of pore channels of RFC. In this study, the $\mathrm{SO}_{3} \mathrm{H}$ was grafted into S-RFC in water at $80{ }^{\circ} \mathrm{C}$ under atmospheric environment. After sulfonation, the pore channels were found to be well preserved as shown in TEM images (Fig S1†) and the well-preserved pore channels could provide abundant reaction places during reactions, which promotes the diffusion and adsorption of xylose molecules. Therefore, S-RFC exhibited better furfural yield and selectivity for the conversion of xylose among the test acid catalysts.

In addition, this work also demonstrates some advantages compared with similar works. Firstly, nontoxic GVL is used as green solvent and GVL itself can be produced from furfural. ${ }^{6}$ It is clear that S-RFC exhibits a comparable, even superior, performance to homogenous catalysis with better recyclability properties. $^{\mathbf{2 0 - 2 5}}$ In addition, 80\% furfural yield is achieved from xylose in $15 \mathrm{~min}$, which is comparable with other heterogeneous catalyst. $^{27-32,47,50}$ Although 93\% furfural is obtained from xylose catalyzed by modified MCM- $41,{ }^{27}$ the furfural yield sharply declined to less than $50 \%$ after first run with catalyst recycling. Besides, $80 \%$ furfural can be obtained using Nafion NR 50 in a biphase system ${ }^{32}$ which is a comparable result with S-RFC, but the reaction time is longer $(1 \mathrm{~h})$ requiring microwave irradiation and an extra addition of cocatalyst ( $\mathrm{NaCl})$. Moreover, SC$\mathrm{CCA}^{47}$ shows a good furfural yield from xylose and corn stalk while the catalyst preparation need isolated 4-BDS as sulfonation reagent. 

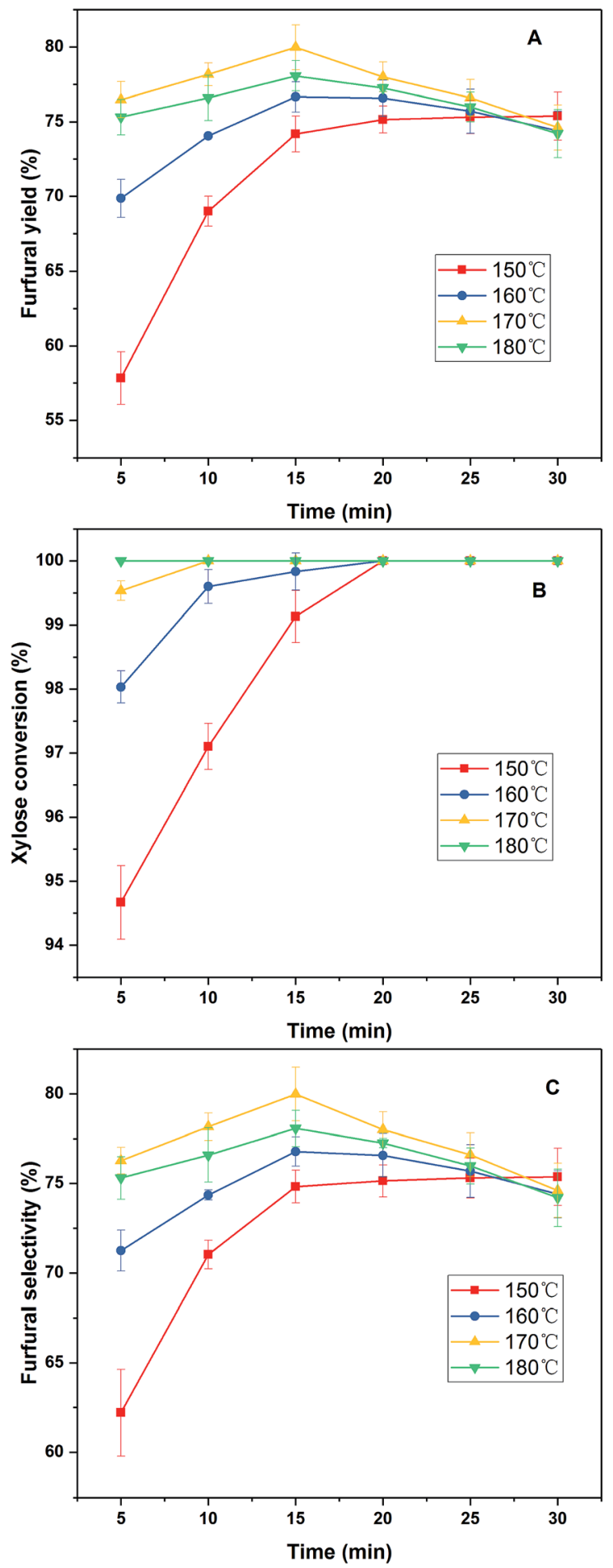

Fig. 1 Effect of temperature and time on furfural production from xylose. Reaction conditions: $0.8 \mathrm{~g}$ xylose, $0.5 \mathrm{~g} \mathrm{~S}-\mathrm{RFC}, 32 \mathrm{ml} \mathrm{GVL}$, 25 min heating-up time.

\section{Effect of catalyst loading}

The effect of catalyst loading on furfural yield was also investigated with a catalyst loading (mass ratio of catalyst/xylose) between $37.5-87.5 \%$ (Fig. 2). The catalyst dosage was of great importance for the conversion of xylose into furfural since only

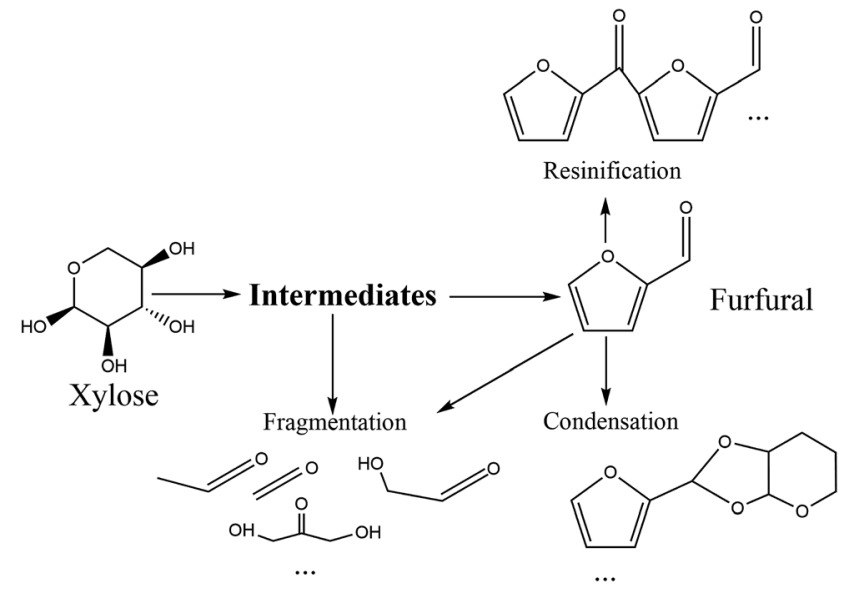

Scheme 1 Conversion of xylose to furfural and plausible reactions in the process.

Table 3 Controlled experiments ${ }^{a}$

\begin{tabular}{llll}
\hline Substrate & Catalyst & Solvent & Furfural yield (\%) \\
\hline $0.8 \mathrm{~g}$ xylose & No catalyst & $32 \mathrm{ml} \mathrm{GVL}$ & Trace \\
$0.8 \mathrm{~g}$ xylose & $0.5 \mathrm{~g} \mathrm{RFC}$ & $32 \mathrm{ml} \mathrm{GVL}$ & Trace \\
$0.8 \mathrm{~g}$ xylose & $0.5 \mathrm{~g} \mathrm{~S}-\mathrm{RFC}$ & $32 \mathrm{ml} \mathrm{GVL}$ & $80.0 \pm 2.1$ \\
$0.8 \mathrm{~g}$ xylose & $0.5 \mathrm{~g} \mathrm{~S}-\mathrm{RFC}$ & $32 \mathrm{ml} \mathrm{GVL}+4 \mathrm{ml} \mathrm{H} \mathrm{H}_{2} \mathrm{O}$ & $69.0 \pm 1.9$ \\
$a^{a} 170{ }^{\circ} \mathrm{C}, 15$ min for all experiments, 25 min heating-up time.
\end{tabular}

trace amount of furfural was obtained in the controlled experiments using no catalyst (Table 3 ). Increasing catalyst dosage had a positive impact on furfural production when the loading was less than $62.5 \%(0.5 \mathrm{~g})$. Furfural yield decreased once the catalyst loading increased beyond $62.5 \%$, which is probably due to superfluous and accessible acid sites allowed for more furfural degradation reactions (fragmentation, resinification and condensation), ${ }^{50-52}$ resulting in the generation of humins or other unknown products as illustrated in Scheme 1.

\section{Reusability of catalyst}

To understand the recyclability of the solid acid, three kinds of catalyst were synthesized by changing the formula among RFC, sulfanilic acid and isoamyl nitrite with a mass ratio of $1: 2: 2$ (S-RFC-1), 1:4:2 (S-RFC-2) and 1:4:4 (S-RFC-3) in the process of sulfonation. Then, a four-cycle experiment was conducted consecutively for each catalyst. After each experiment, the catalyst was separated by filtration, followed by wash with water and acetone and drying in oven for next run.

The recycling experiments were carried out at $170{ }^{\circ} \mathrm{C}$ in 10 min rather than 15 min since the difference in furfural yield between these time periods was small ( $78 \%$ vs. $80 \%$ ) as shown in Fig. 1. Also, $0.6 \mathrm{~g}$ S-RFC was used instead of $0.5 \mathrm{~g}$ to minimize the effect caused by catalyst loss after each run. The results are shown in Fig. 3. The yield of furfural declined slightly in each recycling run, which might be attributed to the leaching of acid sites, but the yield did not change significantly between the four runs. Specifically, S-RFC-2 (1:4:2) gave the best yield during all 
Table 4 Effect of water addition on furfural production ${ }^{a}$

\begin{tabular}{|c|c|c|c|c|}
\hline Time (min) & Solvent & Xylose conversion (\%) & Furfural yield (\%) & Furfural selectivity (\%) \\
\hline 15 & $32 \mathrm{ml} \mathrm{GVL}$ & $99.0 \pm 0.5$ & $80.0 \pm 2.1$ & $80.8 \pm 1.7$ \\
\hline 15 & $32 \mathrm{ml} \mathrm{GVL}+2 \mathrm{ml} \mathrm{H}_{2} \mathrm{O}$ & $99.0 \pm 0.5$ & $78.5 \pm 2.0$ & $79.3 \pm 1.6$ \\
\hline 15 & $32 \mathrm{ml} \mathrm{GVL}+6 \mathrm{ml} \mathrm{H}_{2} \mathrm{O}$ & $90.5 \pm 1.0$ & $54.0 \pm 1.2$ & $59.3 \pm 1.0$ \\
\hline 15 & $32 \mathrm{ml} \mathrm{GVL}+8 \mathrm{ml} \mathrm{H}_{2} \mathrm{O}$ & $68.9 \pm 1.5$ & $32.0 \pm 1.4$ & $46.4 \pm 1.0$ \\
\hline 15 & $32 \mathrm{ml} \mathrm{GVL}+10 \mathrm{ml} \mathrm{H}_{2} \mathrm{O}$ & $61.2 \pm 2.0$ & $24.1 \pm 1.1$ & $39.4 \pm 0.5$ \\
\hline 30 & $32 \mathrm{ml} \mathrm{GVL}+6 \mathrm{ml} \mathrm{H}_{2} \mathrm{O}$ & $97.0 \pm 0.5$ & $63.0 \pm 1.4$ & $65.0 \pm 1.1$ \\
\hline 40 & $32 \mathrm{ml} \mathrm{GVL}+6 \mathrm{ml} \mathrm{H}_{2} \mathrm{O}$ & $99.0 \pm 0.5$ & $60.0 \pm 1.6$ & $60.6 \pm 1.3$ \\
\hline
\end{tabular}

Table 5 Furfural production from xylose using various catalysts ${ }^{a}$

\begin{tabular}{llll}
\hline Entry & Catalyst & Furfural yield (\%) & $\begin{array}{l}\text { Xylose conversion } \\
(\%)\end{array}$ \\
\hline 1 & PTSA-POM & $72.5 \pm 1.5$ & $99 \% \pm 0.5$ \\
2 & Amberlyst-15 & $64.8 \pm 1.5$ & $99 \% \pm 0.5$ \\
3 & $\mathrm{H}-\mathrm{Beta}$ & $78.0 \pm 1.2$ & $99 \% \pm 0.5$ \\
4 & $\mathrm{PTSA}^{\circ} \cdot \mathrm{H}_{2} \mathrm{O}^{b}$ & $74.0 \pm 1.6$ & $99 \% \pm 0.5$ \\
5 & $\mathrm{H}_{2} \mathrm{SO}_{4}{ }^{c}$ & $73.0 \pm 2.2$ & $99 \% \pm 0.5$ \\
6 & $\mathrm{HCl}^{b}$ & $68.0 \pm 1.9$ & $98 \% \pm 0.5$ \\
7 & $\mathrm{~S}$-RFC & $80.0 \pm 2.1$ & $99 \% \pm 0.5$
\end{tabular}

${ }^{a}$ Reaction conditions: $0.5 \mathrm{~g}$ different acid catalyst, $0.8 \mathrm{~g}$ xylose, $32 \mathrm{ml}$ GVL, $170{ }^{\circ} \mathrm{C}, 15 \mathrm{~min}$ reaction time, $25 \mathrm{~min}$ heating-up time. ${ }^{b} 0.215 \mathrm{mmol} \mathrm{HCl}$ and PTSA $\cdot \mathrm{H}_{2} \mathrm{O}$ (corresponding to $0.25 \mathrm{~g}$ S-RFC). ${ }^{c} 0.1075 \mathrm{mmol} \mathrm{H}_{2} \mathrm{SO}_{4}$ (corresponding to $0.25 \mathrm{~g} \mathrm{~S}-\mathrm{RFC}$ ).

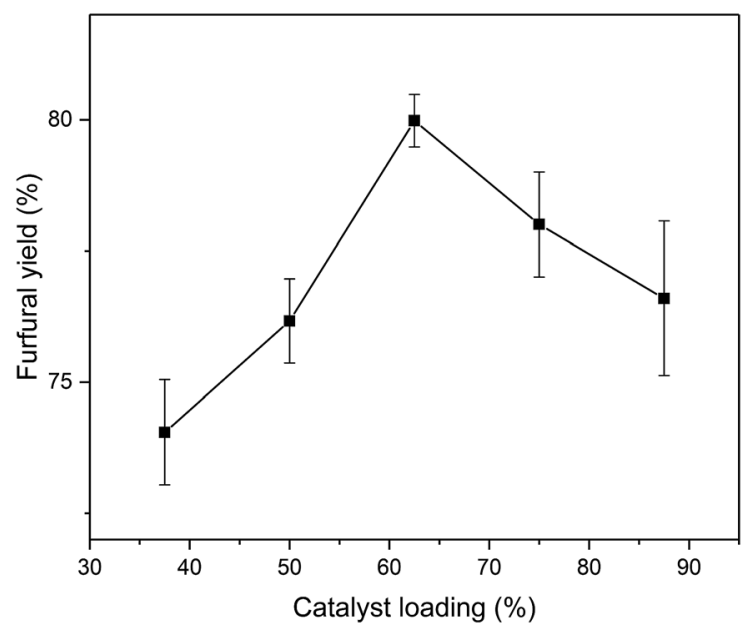

Fig. 2 Effect of catalyst loading (mass ratio of catalyst/xylose) on furfural production from xylose. Reaction conditions: $0.8 \mathrm{~g}$ xylose, $32 \mathrm{ml} \mathrm{GVL}, 170{ }^{\circ} \mathrm{C}, 15 \mathrm{~min}, 500 \mathrm{rpm}, 25 \mathrm{~min}$ heating-up time.

runs, which was chose as optical formula and applied in all other experiments. However, the differences among the three catalysts in terms of furfural yield and recyclability are relatively small.

To further understand the deactivation of S-RFC, a five-cycle consecutive recycling was conducted with $0.8 \mathrm{~g}$ xylose and

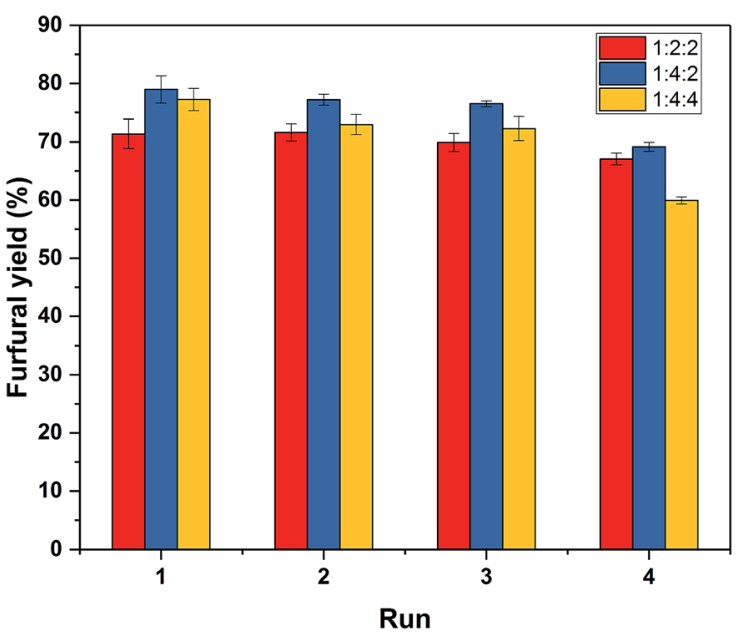

Fig. 3 Reusability of S-RFC- $x(x=1,2,3)$. Reaction conditions: $0.6 \mathrm{~g}$ catalyst, $0.8 \mathrm{~g}$ xylose, $32 \mathrm{ml} \mathrm{GVL}, 170{ }^{\circ} \mathrm{C}, 10 \mathrm{~min}$.

$0.6 \mathrm{~g} \mathrm{~S}-\mathrm{RFC}$ in $32 \mathrm{ml} \mathrm{GVL}$ at $170{ }^{\circ} \mathrm{C}$ for a shorter reaction time of $5 \mathrm{~min}$. The result was shown in ESI (Table S1†). The furfural yield decreased slightly in former four runs and reduced remarkably at $5^{\text {th }}$ run, indicating that the S-RFC deactivated seriously after $4^{\text {th }}$ reusability. No obvious mass addition was observed for reused catalyst after recycling experiments, suggesting that the deposits is not the main cause for the deactivation of S-RFC. In addition, the sulfur content of reused catalyst was measured by an Elementar (EA, Elementar model Vario EL III), which was shown in ESI (Table $\mathrm{S} 2 \dagger$ ). It is observed that the $\mathrm{S}$ content decreases gradually in former four runs and remarkably decreases at run 5, suggesting the partial leaching of $\mathrm{SO}_{3} \mathrm{H}$ after reaction, which also explains the deactivation of S-RFC. Similarly, some other acid catalysts ${ }^{50,53}$ also suffered from the deactivation and the regeneration was attempted. Regeneration of reused S-RFC was attempted by removal of deposits or replenishing the $\mathrm{S}$ lost with a new sulfonation cycle. However, the activity of deactivated S-RFC cannot be recovered by these two ways (Table S1 $\dagger$ ). Currently, the S-RFC can only be reused for four runs with a furfural yield of above $70 \%$. The stability and regeneration of S-RFC still needs to be studied in a further step. 


\section{Influence of substrate concentration on furfural production}

Experiments with different substrate concentration were conducted using S-RFC under optimized reaction conditions. The results are shown in Table 6. 67.4\% furfural yield was obtained when $4.8 \%$ xylose was employed and only $18 \%$ furfural yield was achieved when $9.6 \%$ corn stover was added. The results demonstrated that the yield loss reactions were more tend to happen with the increase of substrate concentration. As illustrated in Scheme 1, we suppose that the condensation between furfural and substrate or intermediates may be the main cause for the decreasing furfural yield. When higher concentration of substrate was employed, more reactants and intermediates would exist in reaction medium, which enlarged the collision between formed furfural and xylose or intermediates. And as a result, more humins and other by-products were formed, leading to lower furfural yield.

\section{Production of furfural from corn stover}

Given the availability and diversity of raw material, corn stover was chosen as a substrate to produce furfural in a one-pot reaction. The reaction was carried out in a well-sealed, mechanically stirred autoclave running at different temperatures $\left(180^{\circ} \mathrm{C}, 190{ }^{\circ} \mathrm{C}, 200{ }^{\circ} \mathrm{C}, 210^{\circ} \mathrm{C}\right)$ with time ranging from $20-$ $140 \mathrm{~min}$ with a mixture of $0.6 \mathrm{~g}$ catalyst, $0.8 \mathrm{~g}$ corn stover and $32 \mathrm{ml} \mathrm{GVL}$. The corn stover used for experiments contained $31.6 \%$ glucan and $20.5 \%$ xylan in accordance with our previous work. ${ }^{54}$ This data was used to calculate the yields of HMF and furfural. Furfural yield exhibited an unambiguous response to residence time and reaction temperature (Fig. 4). A comparison of Fig. 4A with Fig. 1A clearly demonstrates the need of prolonging time and increasing temperature for the conversion of corn stover directly to furfural. The highest furfural yield $(68.6 \%)$ was obtained at $200{ }^{\circ} \mathrm{C}$ for $100 \mathrm{~min}$ as contrasted to high xylose conversion at $170{ }^{\circ} \mathrm{C}$ with $15 \mathrm{~min}$. The prolonged time and increased temperature are expected as xylan in corn stover needs to be hydrolyzed to xylose before it can be converted to furfural. The lower yield of furfural $(68.6 \%$ from corn stover versus $80 \%$ for xylose) is also expected as the higher temperature and prolonged time cause some decomposition of furfural as shown in Fig. 1A and 4A.
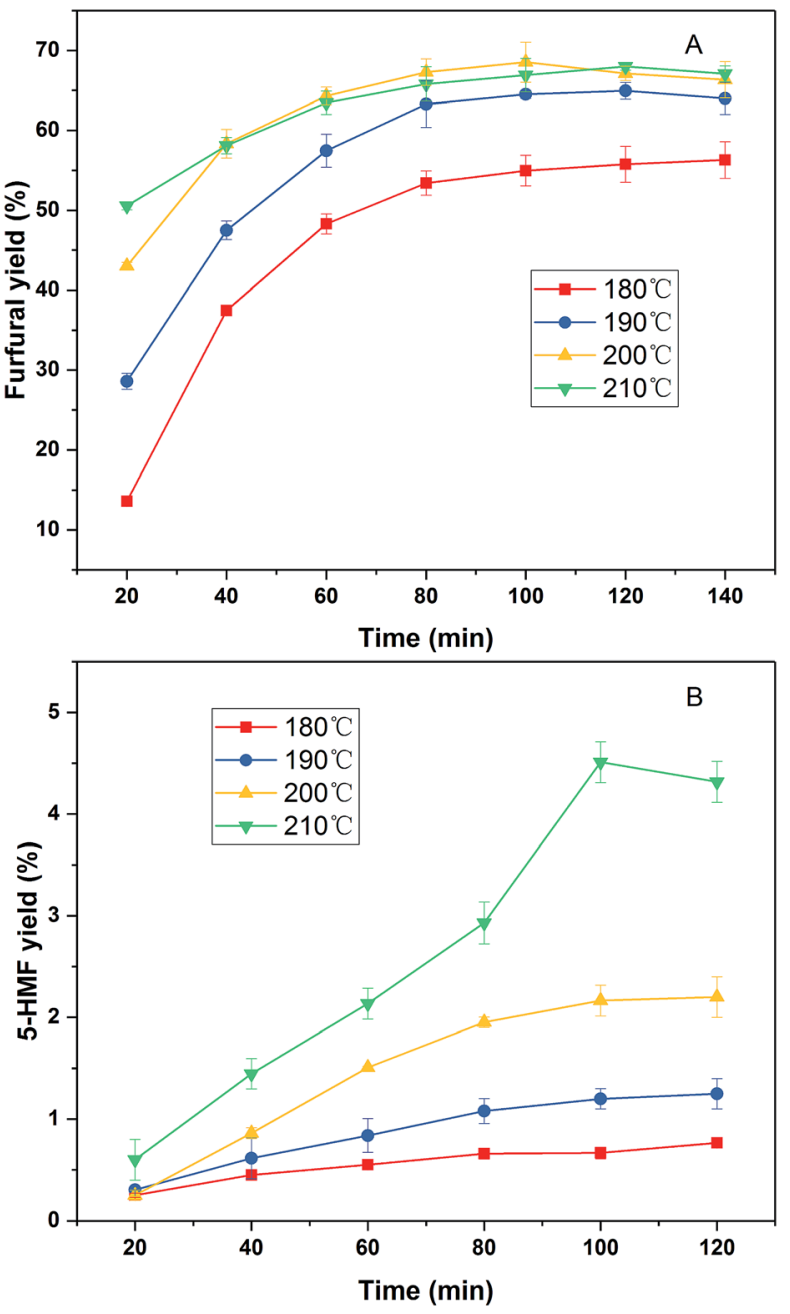

Fig. 4 Furfural production from corn stover. Reaction conditions: $0.6 \mathrm{~g}$ S-RFC, $0.8 \mathrm{~g}$ corn stover, $32 \mathrm{ml} \mathrm{GVL}, 30 \mathrm{~min}$ heating-up time.

Despite, a lower yield of $68.6 \%$ for direct conversion of corn stover to furfural, the results indicate that furfural is relative stable even at $200{ }^{\circ} \mathrm{C}$ for $100 \mathrm{~min}$, demonstrating the efficacy of GVL as a solvent for furfural production.

Table 6 Effects of substrate concentration on furfural production ${ }^{a}$

\begin{tabular}{|c|c|c|c|}
\hline Substrate (wt\%) & Catalyst & Reaction conditions & Furfural yield (\%) \\
\hline $2.4 \mathrm{wt} \%$ xylose & $0.5 \mathrm{~g} \mathrm{~S}-\mathrm{RFC}$ & $170{ }^{\circ} \mathrm{C}, 15 \mathrm{~min}, 32 \mathrm{ml} \mathrm{GVL}$ & $80.0 \pm 2.1$ \\
\hline $3.6 \mathrm{wt} \%$ xylose & $0.5 \mathrm{~g} \mathrm{~S}-\mathrm{RFC}$ & $170{ }^{\circ} \mathrm{C}, 15 \mathrm{~min}, 32 \mathrm{ml} \mathrm{GVL}$ & $72.0 \pm 1.8$ \\
\hline 4.8 wt $\%$ xylose & $0.5 \mathrm{~g}$ S-RFC & $170{ }^{\circ} \mathrm{C}, 15 \mathrm{~min}, 32 \mathrm{ml} \mathrm{GVL}$ & $67.4 \pm 1.5$ \\
\hline $6.0 \mathrm{wt} \%$ xylose & $0.5 \mathrm{~g}$ S-RFC & $170^{\circ} \mathrm{C}, 15 \mathrm{~min}, 32 \mathrm{ml} \mathrm{GVL}$ & $55.0 \pm 1.1$ \\
\hline $7.2 \mathrm{wt} \%$ xylose & $0.5 \mathrm{~g} \mathrm{~S}-\mathrm{RFC}$ & $170{ }^{\circ} \mathrm{C}, 15 \mathrm{~min}, 32 \mathrm{ml} \mathrm{GVL}$ & $40.0 \pm 1.2$ \\
\hline $9.6 \mathrm{wt} \%$ xylose & $0.5 \mathrm{~g} \mathrm{~S}-\mathrm{RFC}$ & $170{ }^{\circ} \mathrm{C}, 15 \mathrm{~min}, 32 \mathrm{ml} \mathrm{GVL}$ & $20.0 \pm 1.0$ \\
\hline $2.4 \mathrm{wt} \%$ corn stover & $0.6 \mathrm{~g} \mathrm{~S}-\mathrm{RFC}$ & $200{ }^{\circ} \mathrm{C}, 100 \mathrm{~min}, 32 \mathrm{ml} \mathrm{GVL}$ & $68.6 \pm 1.6$ \\
\hline $4.8 \mathrm{wt} \%$ corn stover & $0.6 \mathrm{~g} \mathrm{~S}-\mathrm{RFC}$ & $200{ }^{\circ} \mathrm{C}, 100 \mathrm{~min}, 32 \mathrm{ml} \mathrm{GVL}$ & $40.0 \pm 1.3$ \\
\hline $7.2 \mathrm{wt} \%$ corn stover & $0.6 \mathrm{~g}$ S-RFC & $200{ }^{\circ} \mathrm{C}, 100 \mathrm{~min}, 32 \mathrm{ml} \mathrm{GVL}$ & $26.2 \pm 1.4$ \\
\hline 9.6 wt $\%$ corn stover & $0.6 \mathrm{~g}$ S-RFC & $200{ }^{\circ} \mathrm{C}, 100 \mathrm{~min}, 32 \mathrm{ml} \mathrm{GVL}$ & $18.0 \pm 1.2$ \\
\hline 12 wt $\%$ corn stover & $0.6 \mathrm{~g}$ S-RFC & $200{ }^{\circ} \mathrm{C}, 100 \mathrm{~min}, 32 \mathrm{ml} \mathrm{GVL}$ & $13.3 \pm 0.8$ \\
\hline
\end{tabular}


Table 7 Effect of water on furfural yield ${ }^{a}$

\begin{tabular}{llll}
\hline Entry & Substrate & Solvent & Furfural yield (\%) \\
\hline 1 & $0.8 \mathrm{~g}$ corn stover & $32 \mathrm{ml} \mathrm{GVL}$ & $68.6 \pm 1.8$ \\
2 & $0.8 \mathrm{~g}$ corn stover & $32 \mathrm{ml} \mathrm{GVL}+4 \mathrm{ml} \mathrm{H} \mathrm{O}_{2} \mathrm{O}$ & $61.5 \pm 1.3$ \\
& &
\end{tabular}

Compared to similar catalytic system, an obvious difference is noted regarding different types of biomasses. For example, $60 \%$ furfural is gained from corn stalk but only $29 \%$ furfural is produced from pinewood. ${ }^{23,47}$ Interestingly, $83.5 \%$ furfural is obtained from corn stalk which is a higher yield than the furfural produced from xylose $(80.4 \%)$. The differences in yield are ascribed to the conversion of cellulose ${ }^{50}$ need to explain this a bit more. However, the phenomenon did not occur in our previous study. ${ }^{47}$ In present work, the acid density played an important role on the direct conversion of biomass to furfural because the acid density of S-RFC $\left(\mathrm{SO}_{3} \mathrm{H} 0.86 \mathrm{mmol} \mathrm{g}^{-1}\right)$ and SC$\mathrm{CCA}^{47}\left(\mathrm{SO}_{3} \mathrm{H} 1.14 \mathrm{mmol} \mathrm{g}^{-1}\right)$ is lower than the density of PTSA$\mathrm{POM}^{50}\left(\mathrm{SO}_{3} \mathrm{H} 2.3 \mathrm{mmol} \mathrm{g}^{-1}\right)$. 68.6\% furfural yield from corn stover is acceptable, but the critical point is how to separate a catalyst from the biomass residue. Introducing magnetism is a promising technique, and the doping of iron into S-RFC is possible in the fabrication process of resorcinol and formaldehyde..$^{55}$ Improving acid density and introducing magnetism are good areas for future work to improve S-RFC.

Influences of water on furfural production from corn stover were also studied and the results are illustrated in Table 7. As seen with the dehydration of xylose, the addition of $11 \%$ of water ( $4 \mathrm{ml}$ water in $32 \mathrm{ml}$ of GVL) reduced furfural yield from corn stover as well. The presence of water accelerates furfural degradation and promotes side reactions, resulting in lower furfural selectivity. Compared to experiments without water, a much darker reaction mixture is observed in the water/GVL system.

No scaling nor sticky agglomerated residue was observed after any of the reactions, allowing it to be concluded that GVL is a good solvent for corn stover dehydration into furfural.

Furthermore, furfural (boiling point: $162{ }^{\circ} \mathrm{C}$ ) can be isolated from GVL (boiling point: $208^{\circ} \mathrm{C}$ ) by distillation, which is an extra advantage over other efficient solvents, such as DMSO (boiling point: $189^{\circ} \mathrm{C}$ ).

A small amount of HMF was also measured during the dehydration of corn stover, which is less than $5 \%$ yield, indicating that a few hexoses was converted (Fig. 4B). The acid strength of the catalytic system was not strong enough to penetrate and hydrolyze crystalline cellulose. In addition, no Lewis acid was present in the system to isomerize the hexoses to fructose, which is an intermediate in the conversion of hexoses to HMF. Ultimately the yield of HMF was too small to be of commercial significance.

\section{Conclusions}

In conclusion, we have prepared a novel, effective, and stable solid acid catalyst via the mild sulfonation of carbon produced by calcining resorcinol-formaldehyde resin. The catalyst exhibited good acid density, specific surface area, pore volume, and average pore diameter of $0.86 \mathrm{mmol} \mathrm{g}^{-1} \mathrm{SO}_{3} \mathrm{H}, 530 \mathrm{~m}^{2} \mathrm{~g}^{-1}$, $0.56 \mathrm{~cm}^{3} \mathrm{~g}^{-1}$, and $4.2 \mathrm{~nm}$ respectively. The resulting catalyst was used to convert xylose and corn stover into furfural in GVL. High furfural yield was obtained from xylose $(80 \%)$ with a reaction time of $15 \mathrm{~min}$ at $170{ }^{\circ} \mathrm{C}$ and corn stover (68.6\%) conversion under similar reaction conditions. After analyzing the recyclability of the catalyst across four consecutive runs, it was concluded that the catalyst retained its activity. In addition to the applications investigated in this paper, the catalyst also displays an enormous potential to be used in other acidcatalyzed reactions and industrial applications.

\section{Acknowledgements}

This study was financially supported by the State Key Program of National Natural Science Foundation of China (51536009), the National Key Technology R\&D Program of China (No. 2015BAD15B06) and the international technology cooperation plan of Anhui (No. 1503062030)

\section{Notes and references}

1 X. Li and P. Wang, ACS Catal., 2016, 6, 7621-7640.

2 J. Xu, X. Xie, J. Wang and J. Jiang, Green Chem., 2016, 18, 3124-3138.

3 G. Kabir and B. H. Hameed, Renewable Sustainable Energy Rev., 2017, 70, 945-967.

4 G. Kumar, S. Shobana, W. H. Chen, Q. V. Bach, S. H. Kim, A. E. Atabani and J. S. Chang, Green Chem., 2017, 19, 44-67.

$5 \mathrm{~K}$. Wu, Y. WU, Y. Chen, H. Chen, J. Wang and M. Yang, ChemSusChem, 2016, 9, 1355-1385.

6 A. W. Bhutto, K. Qureshi, R. Abro, K. Harijan, Z. Zhao, A. A. Bazmi, T. Abbas and G. Yu, RSC Adv., 2016, 6, 3214032170.

7 C. Sánchez, L. Serrano, M. A. Andres and J. Labidi, Ind. Crops Prod., 2013, 42, 513-519.

8 M. J. Gilkey, P. Panagiotopoulou, A. V. Mironenko, G. R. Jenness, D. G. Vlachos and B. Xu, ACS Catal., 2015, 5, 3988-3994.

9 S. Srivastava, G. C. Jadeja and J. Parikh, RSC Adv., 2016, 6, 1649-1658.

10 L. Bui, H. Luo, W. R. Gunther and Y. Román-Leshkov, Angew. Chem., Int. Ed., 2013, 52, 8022-8025.

11 W. Wu, Y. Xu, S. Chang, J. Deng and Y. Fu, ChemCatChem, 2016, 8, 3375-3380.

12 B. Hernández, J. Iglesias, G. Morales, M. Paniagua, C. LópezAguado, J. L. G. Fierro, P. Wolf, I. Hermans and J. A. Melero, Green Chem., 2016, 18, 5777-5781.

13 T. Wang, K. Li, Q. Liu, Q. Zhang, S. Qiu, J. Long, L. Chen, L. Ma and Q. Zhang, Appl. Energy, 2014, 136, 775-780.

14 N. Alonso-Fagúndez, I. Agirrezabal-Telleria, P. L. Arias, J. L. G. Fierro, R. Mariscal and M. L. Granados, RSC Adv., 2014, 4, 54960-54972.

15 X. Li, X. Lan and T. Wang, Catal. Today, 2016, 276, 97-104. 16 X. Li, B. Ho and Y. Zhang, Green Chem., 2016, 18, 2976-2980. 
17 J. M. Tukacsa, M. Bohusa, G. Dibób and L. T. Mika, RSC Adv., 2017, 7, 3331-3335.

18 Y. Yang, J. Ma, X. Jia, Z. Du, Y. Duan and J. Xu, RSC Adv., 2016, 6, 51221-51228.

19 H. J. Brownlee and C. S. Miner, Ind. Eng. Chem., 1948, 40, 201-204.

20 V. Choudhary, S. I. Sandler and D. G. Vlachos, ACS Catal., 2012, 2, 2022-2028.

21 F. Delbecq, Y. Wang and C. Len, J. Mol. Catal. A: Chem., 2016, 423, 520-525.

22 S. Le Guenic, F. Delbecq, C. Ceballos and C. Len, J. Mol. Catal. A: Chem., 2015, 410, 1-7.

23 Y. Yang, C. W. Hu and M. M. Abu-Omar, ChemSusChem, 2012, 5, 405-410.

24 K. R. Enslow and A. T. Bell, Catal. Sci. Technol., 2015, 5, 28392847.

25 A. V. Carvalhoab, A. M. da Costa Lopes and R. Bogel-Łukasik, RSC Adv., 2015, 5, 47153-47164.

26 I. Agirrezabal-Telleria, J. Requies, M. B. Güemez and P. L. Arias, Appl. Catal., B, 2014, 145, 34-42.

27 S. Kaiprommarat, S. Kongparakul, P. Reubroycharoen, G. Guan and C. Samart, Fuel, 2016, 174, 189-196.

28 H. Li, J. Ren, L. Zhong, R. Sun and L. Liang, Bioresour. Technol., 2015, 176, 242-248.

29 S. M. Bruce, Z. Zong, A. Chatzidimitriou, L. E. Avci, J. Q. Bond, M. A. Carreon and S. G. Wettstein, J. Mol. Catal. A: Chem., 2016, 422, 18-22.

30 X. Hu, R. J. Westerhof, D. Dong, L. Wu and C. Z. Li, ACS Sustainable Chem. Eng., 2014, 2, 2562-2575.

31 W. Jeon, C. Ban, J. E. Kim, H. C. Woo and D. H. Kim, J. Mol. Catal. A: Chem., 2016, 423, 264-269.

32 S. Le Guenic, D. Gergela, C. Ceballos, F. Delbecq and C. Len, Molecules, 2016, 21, 1102.

33 M. Toda, A. Takagaki, M. Okamura, J. N. Kondo, S. Hayashi, K. Domen and M. Hara, Nature, 2005, 438, 178.

34 L. Yan, N. Liu, Y. Wang, H. Machida and X. Qi, Bioresour. Technol., 2014, 173, 462-466.

35 C. de la Calle, J. M. Fraile, E. García-Bordejé, E. Pires and L. Roldán, Catal. Sci. Technol., 2015, 5, 2897-2903.
36 J. Zou, D. Cao, W. Tao, S. Zhang, L. Cui, F. Zeng and W. Cai, RSC Adv., 2016, 6, 49528-49536.

37 M. Zhang, A. Sun, Y. Meng, L. Wang, H. Jiang and G. Li, Microporous Mesoporous Mater., 2015, 204, 210-217.

38 R. Liu, X. Wang, X. Zhao and P. Feng, Carbon, 2008, 46, 16641669.

39 R. Ryoo, S. H. Joo and S. Jun, J. Phys. Chem. B, 1999, 103, 7743-7746.

40 J. Feng, W. Song, L. Sun and L. Xu, RSC Adv., 2016, 6, 110337110343.

41 B. K. Price, J. M. Tour and J. Am, Chem. Soc., 2006, 128, 12899-12904.

42 J. Xu, A. Wang and T. Zhang, Carbon, 2012, 50, 1807-1816.

43 S. G. Wettstein, D. M. Alonso, Y. Chong and J. A. Dumesic, Energy Environ. Sci., 2012, 5, 8199-8203.

44 E. I. Gürbüz, J. M. R. Gallo, D. M. Alonso, S. G. Wettstein, W. Y. Lim and J. A. Dumesic, Angew. Chem., Int. Ed., 2013, 52, 1270-1274.

45 D. M. Alonso, J. M. R. Gallo, M. A. Mellmer, S. G. Wettstein and J. A. Dumesic, Catal. Sci. Technol., 2013, 3, 927-931.

46 M. Chia and J. A. Dumesic, Chem. Commun., 2011, 47, 1223312235.

47 T. Zhang, W. Li, Z. Xu, Q. Liu, Q. Ma, H. Jameel, H. M. Chang and L. Ma, Bioresour. Technol., 2016, 209, 108-114.

48 W. Zhang, H. Tao, B. Zhang, J. Ren, G. Lu and Y. Wang, Carbon, 2011, 49, 1811-1820.

49 Q. Shu, J. Gao, Z. Nawaz, Y. Liao, D. Wang and J. Wang, Appl. Energy, 2010, 87, 2589-2596.

50 Z. Xu, W. Li, Z. Du, H. Wu, H. Jameel, H. M. Chang and L. Ma, Bioresour. Technol., 2015, 198, 764-771.

51 L. Zhang, G. Xi, J. Zhang, H. Yu and X. Wang, Bioresour. Technol., 2017, 224, 656-661.

52 A. S. Dias, M. Pillinger and A. A. Valente, Microporous Mesoporous Mater., 2006, 94, 214-225.

53 L. Zhang, G. Xi, K. Yu, H. Yu and X. Wang, Ind. Crops Prod., 2017, 98, 68-75.

54 Q. Liu, W. Li, Q. Ma, S. An, M. Li, H. Jameel and H. M. Chang, Bioresour. Technol., 2016, 211, 435-442.

55 T. M. Zhang, D. L. Zhao, L. Yin and Z. M. Shen, J. Alloys Compd., 2010, 508, 147-151. 